\title{
Mental Health Status of Undergraduate Students: A Scenario in a Medical College of Kolkata.
}

\author{
Debadatta Chakrabarty ${ }^{1}$, Saikat Bhattacharya ${ }^{1}$, Krishnadas Bhattacharyya ${ }^{2}$, \\ Raju Singh \\ ${ }^{I}$ Assistant Professor, Community Medicine, Medical College, Kolkata \\ ${ }^{2}$ Professor, Community Medicine, Medical College, Kolkata \\ ${ }^{3}$ Junior resident $3^{\text {rd }}$ year, Community Medicine, Medical College, Kolkata
}

\begin{abstract}
Mental health problems are as common among students as they are in the general population. Mental disorders account for nearly $12 \%$ of the global burden of disease. Mental health problems of medical students are a neglected domain still now. So an Observational, descriptive institution based cross sectional study was undertaken to determine the prevalence of mental distress, anxiety and depression \& to find out socio-demographic factors \& academics related factors among the undergraduate students of Medical College, Kolkata, India using a questionnaire containing General Health Questions (GHQ-12), Zung Self Rating Anxiety Scale, Zung self-rating Depression scale. 56\% of them were adolescents and $67.8 \%$ were male students. $14.5 \%$ of the students were smokers. $11.7 \%$ were current alcoholics. Around 5\% of the students chew tobacco while $2.1 \%$ of them have other kinds of addictions like cannabis, cough syrup, etc. About $70 \%$ of the students find it difficult to manage the pressure of the MBBS course.37.3\% of the students were here out of their own wish. About $54 \%$ of the study population has a lack of concentration in studies, while about $43 \%$ have a lack of interest.10.5\% students were severely distressed. Students suffer from academics related stress the most. $15.6 \%$ students were feeling anxious \& $12 \%$ Medical students were suffering from depression. So it is necessary that regular career counseling \& practice of stress coping mechanisms should be made available for the undergraduate medical students at medical college levels.
\end{abstract}

Keywords: Depression, Anxiety, Stress, MBBS examination, addiction

\section{Introduction}

Mental Health is one of the three important aspects of health, incorporating following abilities like adjusting to one's environment pleasantly without being disturbed, fully utilizing one's talents in creative work and help others to do the same etc.

The problem is gradually on the rise due to such factors as urbanization, industrialization and increase in lifespan, together with breakup of the joint family system, which has increased the psychiatric problems of the population as a whole. Mental health problems are as common among students as they are in the general population.

Mental disorders account for nearly $12 \%$ of the global burden of disease. By 2020, it is likely to account for 15\% DALY loss from $6.1 \%$ in 1993 and expected to become second most important cause of disability in the world. ${ }^{1}$

Mental health problems of medical students are a neglected domain still now. Stress that begin in the student period may continue to future life and if adjustments are not made, then inevitably detrimental effects will occur.

So thisstudy was undertaken with the objectives to determine different socio-demographic factors, academics related factors \& the prevalence of mental distress, anxiety and depression among the undergraduate medical students of Medical College, Kolkata, India.

\section{Methodology}

The study was an observational, descriptive and institution based study having a total sample size of 332 students encompassing the $2^{\text {nd }}, 4^{\text {th }}, 6^{\text {th }}$ and $8^{\text {th }}$ semesters done from March to May,2016. Among the total 900 students these were selected by stratified random sampling method using the random number table on each semester's class register.

After obtaining written consent from IEC and verbal consent from students study was conducted with aPredesigned, pre tested, semi structured, self-administered questionnaire containing validated questionnaires like General Health Questions (GHQ-12), Zung Self-Rating Anxiety Scale and Zung Self-Rating Depression Scale . Data was compiled in Microsoft Excel 2007 and analyzed using appropriate statistical methods like number, percentage, etc. 


\section{Results}

In this study of 332 students, $56 \%$ of them were below the age of 19 years and $67.8 \%$ were male students. Hostelites accounted for $39.1 \%$ of the study subjects while $43.4 \%$ stayed with their parents here in Kolkata. $38.4 \%$ of the students had a family income of < Rs. 50,000. More than $75 \%$ students were from nuclear families.

$14.5 \%$ of the students are smokers. $11.7 \%$ are current alcoholics while $0.6 \%$ have left the habit. Around $5 \%$ of the students chew tobacco while $0.9 \%$ has stopped it. $2.1 \%$ of them have other kinds of addictions like cannabis, cough syrup, etc. but none of them has stopped it.

About $70 \%$ of the students find it difficult to manage the pressure of the MBBS course \& $74.1 \%$ students find the University MBBS examination difficult. Though most of the undergraduate students think that the class hours are adequate enough for them to manage, about $47 \%$ think that it is lengthy.37.3\% of the students are here out of their own wish while almost $23 \%$ are here since their parents/families wanted them to become doctors. About $54 \%$ of the study population has a lack of concentration in studies, while about $43 \%$ have a lack of interest.53.6\% of the students do not have any idea competition that one encounters in clearing their PG entrance examinations while almost $39.3 \%$ of them find it difficult to clear.

$10.5 \%$ students are severely distressed. Students suffer from academics related stress the most.Overall $15.6 \%$ students are feeling anxious. About $12 \%$ Medical students are suffering from depression.

\section{Tables}

Table 1: Socio demographic factors of Undergraduate Medical Students $(n=332)$

\begin{tabular}{|l|l|l|l|}
\hline Characteristics & & Frequency & Percentage \\
\hline \multirow{3}{*}{ Age group } & $\leq 19$ & 186 & 56.0 \\
\cline { 2 - 4 } & $20-21$ & 127 & 38.3 \\
\cline { 2 - 4 } & $\geq 22$ & 19 & 5.7 \\
\hline \multirow{3}{*}{ Gender } & FEMALE & 107 & 32.2 \\
\cline { 2 - 4 } & MALE & 225 & 67.8 \\
\hline \multirow{3}{*}{ TYPE OF FAMILY Income(Rs.) } & 550000 & 118 & 38.4 \\
\cline { 2 - 4 } & $50000-100000$ & 115 & 37.5 \\
\cline { 2 - 4 } & $>100000$ & 74 & 26.1 \\
\hline \multirow{3}{*}{ PRESENT RESIDENCE } & NUCLEAR FAMILY & 256 & 77.1 \\
\cline { 2 - 4 } & JOINT FAMILY & 72 & 21.7 \\
\cline { 2 - 4 } & 3 GENERATION FAMILY & 4 & 39.1 \\
\cline { 2 - 4 } & HOSTEL & 130 & 43.4 \\
\cline { 2 - 4 } & WITH PARENTS & 144 & 4.3 \\
\cline { 2 - 4 } & PAYING GUESTS & 44 & 14 \\
\cline { 2 - 4 } & WITH OTHER RELATIVES & 1.2 & \\
\hline
\end{tabular}

Table 2: Substance abuse among under graduate Medical students $(n=332)$

\begin{tabular}{|l|l|l|l|}
\hline SUBSTANCE ABUSE & EVER & \multirow{2}{*}{$\begin{array}{l}\text { NEVER } \\
\text { n }(\%)\end{array}$} \\
\cline { 2 - 3 } & $\begin{array}{l}\text { CURRENT } \\
\mathrm{N}(\%)\end{array}$ & $\begin{array}{l}\text { PAST } \\
\mathrm{N}(\%)\end{array}$ & \\
\hline Smoking & $43(13.0)$ & $5(1.5)$ & $284(85.5)$ \\
\hline Chewing tobacco & $17(5.1)$ & $3(0.9)$ & $312(94.0)$ \\
\hline Alcohol & $39(11.7)$ & $2(0.6)$ & $291(87.7)$ \\
\hline Others* & $7(2.1)$ & $0(0.0)$ & $325(97.9)$ \\
\hline
\end{tabular}

Table 3: Academics related factors among under graduate Medical students $(n=332)$

* multiple response

\begin{tabular}{|l|l|l|}
\hline Characteristics & N & \% \\
\hline Reasons to study MBBS* & & \\
\hline Own wish & 125 & 37.4 \\
\hline Family pressure & 76 & 22.9 \\
\hline Social work & 78 & 23.3 \\
\hline Financial gain & 35 & 10.3 \\
\hline Don't know & 28 & 8.1 \\
\hline Perception about MBBS course & & \\
\hline Easy & 89 & 26.8 \\
\hline Manageable & 10 & 3.0 \\
\hline Difficult to manage & 233 & 70.2 \\
\hline Class Hours & & \\
\hline Lengthy & 158 & 47.6 \\
\hline OK & 162 & 48.8 \\
\hline Short & 12 & 3.6 \\
\hline Lack of concentration & & \\
\hline No & 150 & 45.9 \\
\hline Yes & 177 & 54.1 \\
\hline
\end{tabular}


Mental Health Status Of Undergraduate Students: A Scenario In A Medical College Of Kolkata.

\begin{tabular}{|l|l|l|}
\hline Lack of Interest & & \\
\hline No & 187 & 57.4 \\
\hline Yes & 139 & 42.6 \\
\hline Perception about University examination & & \\
\hline Easy & 72 & 21.7 \\
\hline Difficult & 246 & 74.1 \\
\hline No idea & 14 & 4.2 \\
\hline Clearance of Post graduate entrance examination & & \\
\hline Easy & 23 & 7.1 \\
\hline Difficult & 127 & 39.3 \\
\hline No Idea & 173 & 53.6 \\
\hline
\end{tabular}

Table 4: Mental morbidities among under graduate Medical students $(\mathrm{n}=332)$

\begin{tabular}{|l|l|l|}
\hline Characteristics & $\mathbf{N}$ & \% \\
\hline Distress (As per GHQ-12) $\mathbf{( n = 3 3 2})$ & & \\
\hline No Distress & 202 & 60.9 \\
\hline Distress & 95 & 28.6 \\
\hline Severe Distress & 35 & 10.5 \\
\hline Anxiety Level (n=326) & & \\
\hline No Anxiety & 275 & 84.4 \\
\hline Mild to Moderate Anxiety & 47 & 14.4 \\
\hline Severe Anxiety & 4 & 1.2 \\
\hline Depression Status (n=318) & & \\
\hline No & 277 & 87.1 \\
\hline Mild to Moderate & 39 & 12.3 \\
\hline Severe & 2 & 0.6 \\
\hline
\end{tabular}

\section{Discussion}

It has long been recognised as involving numerous stressors that can affect the wellbeing of the student. ${ }^{2}$ Psychological morbidities like mental distress, different level of anxiety and depression are imposed on to the physician -in- training. In the present study result also, showed that the considerable level of depression, anxiety and mental distress prevails among the study subjects which is in consonance with earlier study conducted in Bhubaneswar, India. ${ }^{3}$ These findings underscore the importance of nurturing a positive learning environment for them.

Another interesting finding in our study was high prevalence of addiction which is $14.5 \%$ for smoking, $12 \%$ for alcohol $6 \%$ for chewing tobacco and $2.1 \%$ for cannabis and drugs. Whether due to increasing mental distress or some other factors it was difficult to find out with this study but is of major concern.

Another finding in our analysis was higher prevalence of anxiety (15.6\%) and depression (12\%) among the students which was consistent with previous study done in agartala India. ${ }^{4}$ The reason could be vast course including clinics and higher expectation from parents. This is of course a paramount concern as it may impair behaviour of students, diminish learning, and ultimately affect patient care after their graduation.

\section{Conclusion}

From this study it can be concluded that regular career counselling and stress coping mechanism should be encouraged for the undergraduate medical students at Medical College level 7.Conflict of interest -none

\section{Reference}

[1]. World Bank. World Development Report 1993. New York: World Bank; 1993.

[2]. Khan MS, Mahmood S, Badshah A, Ali S9. u, Jamal Y. Prevalence of depression, anxiety and their associated factors among medical students in Karachi, Pakistan. J Pak Med Assoc2006; 56 : 583-6.

[3]. S. Iqbal, S.Gupta,E. Venkatarao:stress, anxiety \& depression among medical undergraduate students \& their socio-demographic correlates,Indian J Med Res 141, March 2015, pp 354-357

[4]. Taranga Reang and HimadriBhattacharjyaA Study to Assess the Emotional Disorders with Special Reference to Stress of Medical Students of Agartala Government Medical College and GovindaBallabh Pant HospitalIndian J Community Med. 2013 Oct-Dec; 38(4): 207-211.doi: 10.4103/0970-0218.120154 